\title{
The Incidence of Vasovagal Response in Spinal Anesthesia during Surgery
}

\author{
Sepideh Vahabi ${ }^{1}$, Siavash Beiranvand ${ }^{1 *}$ and Badiozaman Radpay ${ }^{2}$ \\ ${ }^{1}$ Faculty of Medicine, Department of Anesthesiology, Lorestan University of Medical Sciences, Khorramabad, Iran \\ ${ }^{2}$ Faculty of Medicine, Department of Anesthesiology, Shaheed Beheshti University of Medical Sciences, Tehran, Iran
}

Submission: December 23, 2017; Published: January 11, 2018

*Corresponding author: Siavash Beiranvand, Assistant Professor Anesthesia, Lorestan University of Medical Sciences, Khorramabad, Iran, Email: dr.s.beiranvand@gmail.com

\begin{abstract}
Objective: Vasovagal symptoms for sinus bradycardia are associated with hypotension in spinal anesthesia or immediately after it without the presence of high levels of anesthetic. Imbalance between sympathetic and parasympathetic control of the heart rate can be the cause of this syndrome. Aim of this study, the incidence of vasovagal reflex and its influencing factors in patients undergoing spinal anesthesia were studied.

Methods: In this descriptive epidemiological study, 284 patients who were candidates for surgery, under spinal anesthesia which was performed after obtaining written consent. Our study tool was a questionnaire that includes variables such as age, sex, and body mass index, the type of surgery, the anesthesia, fasting time, the positions immediately after spinal anesthesia, ASA class and whether elective or emergency, respectively. Heart and blood pressure were monitored in spinal anesthesia patients. Symptoms of bradycardia and hypotension with loss of consciousness, without anesthesia level above the T10 positively were recorded and the data collected were analyzed with SPSS software.

Results: The incidence of vasovagal response in our study population was 4\%. In our study between age, sex, BMI, ASA class, anesthesia level S1-S5 and having a history of vasovagal reflex and reflexes shows a significant differences $(\mathrm{P}<0.05)$. On the contrary, the type of surgery, duration of fasting before surgery, the patient and the type of positions being elective or emergency surgery, showed that there was no significant relationship $(\mathrm{P}<0.05)$.
\end{abstract}

Conclusion: The incidence of vasovagal response in younger people, male as well as people who have a higher BMI is higher. The rate of vasovagal response in patients who have an underlying disease is more. To prevent vasovagal response, measures such as proper hydration before anesthesia, patient monitoring and knowing the history of previous attacks is frequently recommended.

Keywords: Vasovagal reflex; Spinal anesthesia; Surgery; Bradycardia; Hypotension; Spinal Anesthesia

\section{Introduction}

Vasovagal reflex, which is also called neurocardiogenic syncope, a condition that is caused as a result of vagus nerve stimulation regardless of the mechanism that triggers its onset is similar in different cases [1,2]. Brain stem cells can be directly or indirectly activated by a stimulus that increases the parasympathetic tone of the nervous system (vagus nerve), causing hemodynamic responses in the following; whole heart that causes heart rate (negative Chrono-tropic effect) and reduced contraction (negative inotropic effect) resulting in decreased heart output, consciousness as a result of an increase in parasympathetic tone, and reduction in blood supply to the brain. At the other end of the spectrum call vasodepressor caused by low blood pressure without much change in heart rate, this phenomenon occurs during vasodilation. Most patients with vasovagal syncope, a mixed response between the two ends of the whole show [3]. Prolonged standing or sitting vasovagal included some stimuli, traumatic stress, any unpleasant or painful stimuli, medical interventions, such as blood, injections and stitches sleep deprivation, exposure to extreme heat, such as registered nursing care rectal temperature, the pressure on the carotid sinus, severe cough, and swallowing [4-6]. Vasovagal response is usually repeated when the person is exposed to certain stimulation. Before losing consciousness there is common experiences and early symptoms such as light headedness, Nausea, feeling hot or too cold, tinnitus, dizziness, weakness and visual disturbances. This symptom occurs for a few seconds before loss of consciousness, usually when a person is sitting or standing. For patients who gain their consciousness, if they tried to sit or stand up again, there may be unconsciousness recurrence. Nausea, sweating and pallor from several minutes to several hours may be in place [7-9].

Anesthesiologists with the incident, has repeatedly encountered in the operating room. Patient anxiety and catheter insertion in regional anesthesia (epidural catheter Embed performed spinal, caudal) may cause reflux $[11,12]$. Spinal 
and epidural anesthesia with an incidence of bradycardia and hypotension associated with bradycardia, but less common vasovagal reactions or asystole, and sudden loss of consciousness can be seen along with them. Delays in treatment and rehabilitation outcome are usually good but could permanently cause brain damage [12-15]. Risk of asystole can exist until after the surgery [16]. The risk of vasovagal reactions during spinal anesthesia is life-threatening $3 / 1000$ persons. $5 \%$ is the incidence of bradycardia and hypotension in spinal anesthesia [17]. To avoid these complications, the previous history of vasovagal and its intensity is important. These side effects may occur during our collection [18-20]. In this study, we intended to study the incidence of vasovagal response during spinal anesthesia for surgery in a general hospital in Khorramabad (city west of Iran).

\section{Method}

This study comprises of population of patients who were under spinal anesthesia, it was a descriptive type of epidemiological study. Inclusion criteria for the study included people over 15 years, patient satisfaction for spinal anesthesia, sensory levels lower than the T10. Exclusion criteria included patient refusal, contraindications to spinal anesthesia and enforcement action to partake in the research by the anesthesiologist more than once. After the approval of the project in the Research and Ethics Committee of the Council of Lorestan University of Medical Sciences, with written consent from the patients in May, patients for elective surgery under spinal anesthesia with lower levels of T10 candidates were enrolled into this study. A questionnaire containing all patient information including gender, age, BMI, type of surgery, fasting time in hours, being elective or emergency surgery, and ASA class history of vasovagal reflex, was asked and recorded before surgery.

The idea was that way after entering the operating room with the patient catheter to the vessel was 18 . The patient was administered with Ringer's lactate serum $15 \mathrm{mg} / \mathrm{kg}$ 30-60 minutes before anesthesia. We monitored patients pulse oximetry, noninvasive measurement of blood pressure and the ECG. Patients received premedication and spinal anesthesia in a sitting position with the needle number 25 of the L4-L5 or L3-L4 space with 5\% lidocaine and was carried out by only one anesthesiologist. The proper position for patients sitting or lying down, the heart rate and blood pressure at intervals of one minute to ten minutes after each block and then every 5 minutes until the end of surgery was recorded. In case of vasovagal syndrome with symptoms of loss of consciousness, bradycardia and hypotension less than 50 primary and lower blood pressure to less than 30\%without area of numbness above the T10 case was positive. Anesthesia level was done with the tip of the needle using pin print evaluation method, at intervals of 5 minutes until the numbness was determined stable. The event frequently requires treatment in such a way that the head position or leg is elevated; liquids and atropine were administered. Epinephrine was administered to a patient in asystole. Measures related to spinal vasovagal time on stage was divided. Classification based on level after spinal anesthesia: a. Group 1: The level of numbness in the area S1-S5,

b. Group II: numbness of the lower level of T10.

\section{Classification based on types of operations}

General surgery: surgery, pilonidal sinus surgery, Fisher surgery, urological surgery: the withdrawal of ureteral stones, TURP, varicocelectomy. Women and gynecologic surgery: repair Cystocels Rectocele/ perineorrhaphy, orthopedic surgery: Surgery on Femur/surgery on the leg/ankle surgery on the legs and feet.

\section{Classification based on the time of vasovagal}

Sitting, moving time of anesthesia, the time of spinal lidocaine injection, immediately after giving Positions, during the surgery.

\section{Classification based on the positioning of the patients during anesthesia after}

Immediately after spinal patient was supine, for the first 3-5 minutes and then sat saddle spinal patients were in positions about 30 degrees above the head.

\section{Classification based on the positioning of the patients during surgery}

Supine, lithotomy, Prone.

After collecting the information, the data were entered into SPSS software and statistical analysis was performed by consulting a statistician.

\section{Results}

During this two-month study of 284 patients who had undergone spinal anesthesia. In terms of gender distribution, $117(41 \%)$ were women and $167(58 \%)$ were men. The mean age of the patients was $38.27 \pm 15.1$ years with a minimum of 18 and maximum of 87 years. Also, the average BMI of the patients was 26.49 9.3.267 patients were elective patients and 17 patients were operated on an emergency basis. Relationships between age, incidence and lack of vasovagal response during spinal anesthesia were compared. Reflex in people who had an average age of $29.85 \pm 8.5$ and the amount of reflux in patients were $36 \pm 15.2$ years. Based on the results of the independent t-test there was a significant difference in terms of average age, thus the incidence of vasovagal response during spinal anesthesia is significantly higher in younger individuals. $(\mathrm{P}=0.03)$ (Table 1$)$

Table 1: Demographic variables in 284 patients of vasovagal response during spinal anesthesia.

\begin{tabular}{|c|c|}
\hline Variables & Prevalence/Mean \\
\hline \multicolumn{2}{|c|}{ Gender } \\
\hline Male & 167 \\
\hline Female & 117 \\
\hline Age (years) & $38.27 \pm 15.1$ \\
\hline BMI & $26.49 \pm 9.3$ \\
\hline \multicolumn{2}{|c|}{ Surgery } \\
\hline Elective & 271 \\
\hline Emergency & 17 \\
\hline
\end{tabular}


The relationship between BMI and the occurrence of reflux during spinal anesthesia were compared. Patients who had an average BMI of reflexes, $31.43 \pm 3.8$ and mean BMI of patients who had reflux was, 25.94 \pm 3.37 . According to independent t-test there was a significant difference between the mean BMI and incidence of reflexes, it can be concluded that the possibility of a vasovagal response in people with higher BMI was higher during spinal anesthesia $(\mathrm{P}=0.001)$ (Table 2). The time of fasting in the absence of reflux were analyzed, the average duration of reflux in patients who had fasted was $9.14 \pm 1.9$ hours and reflux in patients who did not fast for $8.98 \pm 1.38$ hours, the independent t-test showed no significant difference between the two groups after the fasting time before surgery, which had no effect on the incidence of vasovagal response $(\mathrm{P}=0.11)$. The effect of gender on the incidence and lack of vasovagal response were evaluated, 2 patients were female and 12 male patients showed reflexes and 115 female patients and 155 male patients had a lack of reflexes. The incidence in women and men was $1.7 \%$ and 7.1 respectively. The Chi-square test shows significant difference between gender and that of means, the incidence of vasovagal reflex in men is significantly higher $(\mathrm{P}=0.03$ ) (Table 3 ).

Table 2: Relationship between Body Mass Index and the occurrence of reflex during spinal anesthesia.

\begin{tabular}{|c|c|}
\hline Variables & Mean \\
\hline BMI & $25.94 \pm 3.37$ \\
\hline Incidence of Reflexes & $31.43 \pm 3.8$ \\
\hline \multicolumn{2}{|c|}{ Duration of Reflex (hrs) } \\
\hline Fasted & $9.14 \pm 1.9$ \\
\hline Not fasted & $8.98 \pm 1.38$ \\
\hline
\end{tabular}

Data are expressed as means $( \pm S D)$

Table 3: Effect of gender on the incidence of vasovagal response.

\begin{tabular}{|c|c|}
\hline Variables & Prevalence \\
\hline \multicolumn{2}{|c|}{ Showing Reflexes } \\
\hline Male & 12 \\
\hline Female & 2 \\
\hline \multicolumn{2}{|c|}{ Lacking Reflexes } \\
\hline Male & 155 \\
\hline Female Incidence of Reflexes \\
\hline Male & 115 \\
\hline Female & $7.10 \%$ \\
\hline
\end{tabular}

The effect of elective or emergency surgery on the incidence and lack of vasovagal response were evaluated. In patients who had undergone elective surgery, patients without any reflexes were 253 and 14 people showed reflexes. The patients who had undergone surgery on an emergency basis at any vasovagal response were 17 people. In assessing the descriptive statistics, the incidence rate in elective surgeries 5.2\%, showed there was no significant difference according to Chi-square test $(\mathrm{P}=0.59)$ (Table 4). The custom of the vasovagal response in anesthesia levels during surgery were evaluated by spinal anesthesia. 198 people were at the level of anesthesia below T10 and 5 people had the reflexes, the descriptive statistics estimate that the incidence was $2.5 \%$. Anesthesia level was 72 at S1-S5, and 9 people gave vasovagal response. The incidence of vasovagal response in this sensory level was $12.5 \%$ according to the Chi-square test, there was a significant difference between the two levels.

Table 4 : Effect of elective or emergency surgery on the incidence and lack of vasovagal response.

\begin{tabular}{|c|c|}
\hline Variable & Prevalence \\
\hline Reflexes & 14 \\
\hline & 253 \\
\hline
\end{tabular}

Table 5: Effect of positioning of the patients.

\begin{tabular}{|c|c|}
\hline Variables & Prevalence \\
\hline Sleeping Position (Supine) & CV184 (2.7\%) \\
\hline Reflex & 5 \\
\hline Non Reflex & 179 \\
\hline Prone Position & $40(12.5 \%)$ \\
\hline Reflex & 5 \\
\hline Non Reflex & 35 \\
\hline Lithotomy Positions & $46(8.6 \%)$ \\
\hline Reflex & 4 \\
\hline Non Reflex & 42 \\
\hline
\end{tabular}

The level of anesthesia S1-S5 caused by spinal anesthesia gave more vasovagal response of the level of anesthesia lower than $\mathrm{T} 10$. As a result the reflex is more prevalent in the lower level of anesthesia. $(\mathrm{P}=0.001)$

The effect of positioning of the patients was evaluated during surgery. Among the 284 patients who received spinal anesthesia for surgery, 184 positions were in sleeping positions, and 5 were reflexes and 179 were non-occurrence of reflux. 40 people were in prone position, 5 cases of reflex and 35 were non-occurrence of reflux. 46 patients were in lithotomy positions, 4 patients showed reflexes, and 42 patients did not develop reflexes. According to estimates of the descriptive statistics, the incidence rate showed $2.7 \%$ in supine position, $12.5 \%$ in prone position, and $8.6 \%$ in the lithotomy position respectively. This reflex was higher in the prone position of the Chi-square test, but, there was no significant correlation between the position and the incidence of reflux (Table 5). Patients in ASA class and the lack of impact of the vasovagal response were evaluated. From the Chi-square test, there was no significant association observed in the field, thus underlying disease and higher.

However the ASA class increases the rate of vasovagal response $(\mathrm{P}=0.01)$ (Table 6). Based on the number of surgical procedures performed in patients with vasovagal response, which was 14 cases, 5 cases (3\%) represent orthopedic surgery (broken leg and ankle),2 patients (4\%) women represent (surgery to repair Cystocels and Rectocele) and 7 patients (6\%) were general 
surgery (5 pilonidal sinus, 1 Fisher 1 hemorrhoidectomy), respectively. The incidence rate shows higher reflexes in general surgery, but based on Fisher's exact test between the type of surgery and the incidence of vasovagal response, there was no significant correlations $(\mathrm{P}=0.266)$ (Table 6). Among the 284 patients studied, 21 had a history of vasovagal syndrome before, among these, 9 (42\%) patients had experienced during the recent study. In patients with a positive history of vasovagal syndrome, that is in a recent study of 263 patients, were 5 (1.9\%) people suffer from this syndrome $(\mathrm{P}=0.001)$, between the index and their reappearance there a history of vasovagal syndrome.

Table 6: Number of surgical procedures performed in patients with vasovagal response.

\begin{tabular}{|c|c|}
\hline Surgical Procedure & Prevalence \\
\hline Orthopedic Surgery (broken leg and ankle) & $5(3 \%)$ \\
\hline Surgery to Repair Cystocels and Rectocele & $2(4 \%)$ \\
\hline General Surgery & $7(6 \%)$ \\
\hline Pilonidal Sinus & 5 \\
\hline Fisher & 1 \\
\hline Emorrhoidectomy & 1 \\
\hline
\end{tabular}

\section{Discussion}

Cardiogenic syncope (vasovagal response) is one of the known side effects of medical interventions.Vasovagal response usually occurs when a person is exposed to certain irritation with symptoms such as bradycardia, hypotension, dizziness, sweating and even asystole [1,2]. In this study, we examined the incidence of vasovagal response during spinal anesthesia for the surgery. Some researchers believe that the possibility of VVR on young people is more [19,21]. In our study, the mean age of patients studied in our vasovagal syndrome were $29.85 \pm 8.5$ years, the incidence of patients who had no reflux was $36 \pm 15.2$ years showing significant differences. But young people more prone to reflux have not been confirmed in all studies. For example, in the study of Professor Tiziana and Carol Cheng in America heart center about neurocardioscopic syncope. From 1980 to 2004, it was observed that neurocardioscopic syncope occurs in 3\% of patients attending emergency cases, that $6 \%$ of all cases were admitted to hospital. 15 percent of them are children under 18 years, and $23 \%$ over 18 years. The incidence of syncope had a direct correlation with increasing age. So that as age is increased, there is an increase in the incidence of vasovagal syncope.

The limitation in our study was that age and patients under the age of 15 years were not evaluated, perhaps because there is consistency in our results in Tiziana study, 63\% of all cases occur frequently in men. The results show a higher prevalence of vasovagal syncope in men [22], in our study the incidence of male to female ratio was 4.1. In another study by Assarian et al. [23] they found that the predisposing factors in the incidence of vasovagal low weight, age, male gender, which can increase the risk of vasovagal reactions with the result of our study is similar age and male gender in the study of Normand et al in 2015 were consistent with this study and others [21]. Yamaha in a study of the object by subject neurocardioscopic syncope after spinal anesthesia was performed. In this study, one of the causes of syncope, the movement of blood in the lower extremities is expressed, which then activates the sympathetic nervous system and thus severe bradycardia or asystole and syncope occur that cause bradycardia in patients due to the above results, although we can also have multiple causes [24,25].

In a study conducted in Japan in 2011 by Tajiri et al. [26] when injected into the epidural catheter, patient suffered a sudden loss of consciousness was associated with asystole The patient is immediately injected with $0.5 \mathrm{mg}$ atropine sulfate and oxygen return to the previous situation. The result of this study is to insert the catheter as one of the factors of vasovagal syncope, and the hypothesis that anxiety caused by pain can lead to vasovagal elevation. The result of this study is to insert a catheter as one of vasovagal syncope and the hypothesis that anxiety caused by pain, can be caused frequently mentioned [26]. We also study a case of male patients undergoing inguinal hernia surgery at the time the spinal needle enters and the anesthetic was injection, dizziness, low blood pressure and sweating resulted, which is different from our study, spinal anesthesia and epidural was done in the study of Tajiri et al. [26] but in the study of caplan et al. [27] they noted the incidence even in healthy people. This research resulted in the death of 14 cases of cardiac arrest and severe brain damage in patients undergoing spinal anesthesia which were reported. The results of the investigation of complaints due to anesthesia during the years 1978-1986 were during the surgery, most of which occurred after the block. At that time, cardiac arrest, heart rate, and blood pressure drop was gradual. On average cardiac arrest occurred in less than 2 minutes. Early signs in order of frequency included bradycardia/ hypotension/cyanosis and loss of consciousness.

In two studies perspective valance and risk factors for bradycardia, and other fairy intraoperative complications were evaluated during spinal anesthesia. In 2700 patients with bradycardia were $10 \%$, Hypotension, $22 \%$ and nausea $10 \%$.None of the patients were not experiencing asystole. The most important factor in the occurrence of these events was sensory level T5-T6, and more. Bradycardia was higher in young and ASA class1 and vice versa, hypotension was higher in the elders. The incidence of bradycardia after a few heartbeats and sudden reversal increases with the switch that increases the venous return which is possible only with the express vasovagal reaction. A study by Mac Kunshan et al. [28] at the University of Manchester in 2009 on the number of patients who were candidates for ureteral stones surgery, sitting positions during spinal anesthesia, was raised as a risk factor and the risk of vasovagal syndrome is increased in this position. Treatment of 107 people in sleeping positions and 127 in prone positions and 50 were in lithotomy positions. The incidence of vasovagal response in sleeping positions $4.6 \%$, while in the lithotomy position $8.0 \%$ and $3.9 \%$ for prone position. According to chi-square test there was no significant differences between the position and reflex this could be due to the low proportion 
of patients who were in sitting positions, lithotomy and saddle positions.

In a study that was conducted by Dresner et al. [29] in the United Kingdom, on 34 women who were cesarean candidates and have had coronary artery disease and hypertension, spinal anesthesia was used. 33 anesthesias were performed successfully and only one was not feasible. In 6 cases $(0.18 \%)$ mild transient hypotension occurred and only one vasovagal syncope were observed for bradycardia and loss of consciousness. The study average risk of heart disease - CVD was vasovagal syncope. In our study, 20 patients were in class II ASA, 3 of them have incidence of reflexes. Out of the 3 people, 2 of them had disease of chronic hypertension and were receiving treatment. The Chisquare test in our study shows a significant relationship between underlying disease and the incidence of vasovagal response which was consistent with the study of Dresner. In a study in 2012 by Laurent et al. [30] in the department of gynecologic in Spain on 4018 women who were undergoing hysteroscopy. 115 cases of complications that require hospitalization period more than $7.2 \%$ of them were suffering from vasovagal syncope. In our study, 284 patients were studied, 14 of them were suffering from vasovagal syncope, which was $4 \%$ according to the study, as compared to our study, and there was a significant difference between the two studies. Predicted and lead to better management of patients after the surgery.

\section{Conclusion}

The incidence of vasovagal response in younger people, male as well as people who have a higher BMI is higher. The rate of vasovagal response in patients who have an underlying disease is more. To prevent vasovagal response, measures such as proper hydration before anesthesia, patient monitoring and knowing the history of previous attacks is frequently recommended.

\section{Acknowledgement}

Financial support was offered by Lorestan University of Medical Sciences, Khoramabad, Iran

\section{Conflict of Interest}

The authors have no conflict of interest

\section{Ethical Approval}

All procedures performed in studies involving human participants were in accordance with the ethical standards of the institutional and/or national research committee and with the 1964 Helsinki Declaration and its later amendments or comparable ethical standards.

\section{Referencces}

1. Srivathsan K, Lee RW (2003) Swallow Syncope. East 26: 2002-2003.

2. Chaudhary A, Parikh H, Dave V (2011) Current scenario: Knowledge of basic life support in medical college. Natl J Med Res 1(2): 80-82.

3. Mordecai MM, Brull SJ (2005) Spinal anesthesia. Curr Opin Anaesthesiol 18: 527-533.
4. Watkins EJ, Dresner M, Calow CE (2000) Severe vasovagal attack during regional anaesthesia for caesarean section. Br J Anaesth 84(1): 118-120.

5. Cyna AM, Andrew M, Emmett RS, Middleton P, Simmons SW (2006) Techniques for preventing hypotension during spinal anaesthesia for caesarean section. Cochrane database Syst Rev 4: CD002251.

6. Gratadour P, Viale JP, Parlow J, Sagnard P, Counioux H, et al. (1997) Sympathovagal effects of spinal anesthesia assessed by the spontaneous cardiac baroreflex. Anesthesiology 87(6): 1359-1367.

7. Hanefeld C, Miebach T, Bulut D, Theodoridis T, Rubenthaler F, et al. (2005) [Effects of lumbar spinal nerve analgesia on the cardiovascular system]. Z Orthop Ihre Grenzgeb 143(1): 86-90.

8. Hanefeld C, Ohlgard P, Miebach T, Kleinert H, Mügge a, et al. (2006) [Acute cardiovascular reactions to cervical nerve root infiltration]. Z Orthop Ihre Grenzgeb 144(1): 27-32.

9. Manchikanti L, Malla Y, Wargo BW, Cash KA, Pampati V, et al. (2012) Complications of fluoroscopically directed facet joint nerve blocks: a prospective evaluation of 7,500 episodes with 43,000 nerve blocks. Pain Physician 15(2): E143-E150.

10. Tolksdorf W, Merkel G, Rehder H, Rey ER, Berlin J (1984) [Psychological aspects of spinal anesthesia. Vasovagal syncope and anxiolytic medication]. Anaesthesist 33(7): 307-310.

11. Schuster P (2006) [Syncope in children and young adults]. Tidsskr Nor Laegeforen 126(17): 2250-2252.

12. Chadwick IS, Eddleston JM, Chandelier CK, Pollard BJ (1993) Haemodynamic effects of the position chosen for the insertion of an epidural catheter. Int J Obstet Anesth 2(4): 197-201.

13. Soltani Mohammadi S, Hassani M, Marashi SM (2014) Comparing the squatting position and traditional sitting position for ease of spinal needle placement: A randomized clinical trial. Anesth Pain Med 4(2): e13969.

14. Siddik Sayyid S, Zbeidy R (2008) Practice guidelines for obstetric anesthesia--a summary. Middle East J Anesthesiol 19(6): 1291-1303.

15. Bilotta F, Stazi E, Zlotnik A, Gruenbaum SE, Rosa G (2014) Neuroprotective effects of intravenous anesthetics: a new critical perspective. Curr Pharm Des 20(34): 5469-5475.

16. Brown EN, Lydic R, Schiff ND (2010) General anesthesia, sleep, and coma. N Engl J Med 363: 2638-2650.

17. Augustin ID, Long TR, Rose SH, Wass CT (2014) Recruitment of house staff into anesthesiology: A longitudinal evaluation of factors responsible for selecting a career in anesthesiology and an individual training program. J Clin Anesth 26(2): 91-105.

18. Barreveld A, Witte J, Chahal H, Durieux ME, Strichartz G (2013) Preventive analgesia by local anesthetics(): The reduction of postoperative pain by peripheral nerve blocks and intravenous drugs. Anesth Analg 116(5): 1141-1161.

19. Masamoto K, Kanno I (2012) Anesthesia and the quantitative evaluation of neurovascular coupling. J Cereb Blood Flow Metab 32(7): 1233-1247.

20. Dozier AM, Howard CR, Brownell EA, Wissler RN, Glantz JC, et al. (2013) Labor epidural anesthesia, obstetric factors and breastfeeding cessation. Matern Child Health J 17(4): 689-698.

21. Noormand R, Shafiee A, Davoodi G, Tavakoli F, Gheini A, et al. (2015) Age and the Head-Up Tilt Test Outcome in Syncope Patients. Res Cardiovasc Med 4(4): e27871.

22. Chen LY, Shen WK (2006) Neurocardiogenic syncope: latest pharmacological therapies. Expert Opin Pharmacother 7(9): 11511162. 
23. Assarian Z, Abed Haghighi B, Javadi I, Fotouhi A, Seighali F AN (2011) Risk factors for vasovagal reactions during blood donation. Sci J Iran Blood Transfus Organ 7(4): 221-226.

24. Ishiyama T, Shibuya K, Terada Y, Iwashita H, Masamune T, et al. (2012) Cardiac arrest after spinal anesthesia in a patient with neurally mediated syncope. J Anesth 26(1): 103-106.

25. Soong C, Chen BH (2015) Syncope confusion. CMAJ 187(7): 521.

26. Tajiri O, Tateda T, Ito H, Yago Y, Kanazawa M (2009) A case of neurocardiogenic syncope with asystole during insertion of epidural catheter. Japanese J Anesthesiol 58(9): 1154-1157.

27. Caplan RA, Ward RJ, Posner K, Cheney FW (1988) Unexpected cardiac arrest during spinal anesthesia: A closed claims analysis of predisposing factors. Anesthesiology 68(1): 5-1.
28. Mcconachie I (1991) Vasovagal asystole during spinal anaesthesia Anaesthesia 46(4): 281-282.

29. Dresner M, Pinder A (2009) Anaesthesia for caesarean section in women with complex cardiac disease: 34 cases using the Braun Spinocath spinal catheter. Int J Obstet Anesth 18(2): 131-136.

30. Povedano B, Arjona JE, Velasco E, Monserrat JA, Lorente J, et al. (2012) Complications of hysteroscopic Essure $(\circledR)$ sterilisation: Report on 4306 procedures performed in a single centre. BJOG An Int J Obstet Gynaecol 119(7): 795-799.

\section{Your next submission with Juniper Publishers} will reach you the below assets

- Quality Editorial service

- Swift Peer Review

- Reprints availability

- E-prints Service

- Manuscript Podcast for convenient understanding

- Global attainment for your research

- Manuscript accessibility in different formats ( Pdf, E-pub, Full Text, Audio)

- Unceasing customer service

Track the below URL for one-step submission https://juniperpublishers.com/online-submission.php 